Journal of Applied Ichthyology

August 2008, Volume 24 Issue 4, Pages 406 - 409

http://dx.doi.org/10.1111/j.1439-0426.2008.01148.x

(c) 2008 Wiley Blackwell Publishing, Inc.
Archimer, archive institutionnelle de l'Ifremer http://www.ifremer.fr/docelec/

\title{
A proposal and case study towards a conceptual approach of validating sperm competition in common carp (Cyprinus carpio L.), with practical implications for hatchery procedures
}

V. Kaspar ${ }^{1,{ }^{*}}$, M. Vandeputte ${ }^{2,3}$, K. Kohlmann ${ }^{4}$, M. Hulak ${ }^{1}$, M. Rodina ${ }^{1}$, D. Gela ${ }^{1}$, M. Kocour ${ }^{1}$ and O. Linhart $^{1}$

${ }^{1}$ Research Institute of Fish Culture and Hydrobiology, University of South Bohemia in Ceske Budejovice, Zatisi, Vodnany, Czech Republic

2 IFREMER, Chemin de Maguelone, Palavas

${ }^{3}$ INRA UR544 Unité de Génétique des Poissons, Jouy en Josas, France

${ }^{4}$ Department of Inland Fisheries, Leibniz-Institute of Freshwater Ecology and Inland Fisheries, Mügelseedamm, Berlin, Germany

*: Corresponding author : V. Kaspar, Tel: +420 383382 402, Fax: +420 383382 396, email address : vkaspar@vurh.jcu.cz 
It has been postulated that sperm competition during the process of fertilization can be considered as part of a nechanism involved in sexual selection that occurs in wide range of animals (Birkhead and Mфller, 1998; Birkhead and Pizzari, 2002). This common phenomenon has an important effect on the reproductive behavior in many animals, including fish with external and internal fertilization.

Parker (1970) defined sperm competition as "competition with a single female between the sperm from two or more males for the fertilization of ova". More recently he re-defined it as "competition between the sperm from two or more males for the fertilization of given set of ova" (Parker, 1998). Furthermore, Parker et al. (1996) also distinguished between the risk and the intensity of sperm competition. The risk of sperm competition refers to the probability that a male will spawn with at least one other male competing for a batch of eggs, whereas the intensity of sperm competition refers to the number of males whose sperm are competing for a batch of eggs. Sperm competition in fish, especially those with external fertilization, is represented by alternative mating strategies (Taborsky 1994; 1998). Many descriptive and functional terms are used to describe these strategies (forum by Taborsky, 1997). There have been different concepts to the assessment of sperm competition in a variety of fish species. Methods to evaluate sperm competition include: studies of reproductive behavior and tactics, particulary in species with two life history strategies (Gross, 1985; Fuller, 1998; Evans and Magurran, 1999; Leach and Montgomerie, 2000; Vladic and Jarvi, 2001; Burness et al., 2004; Reichard et al., 2004), comparative studies of sperm competition across species with external fertilization, evaluation of the intensity of competition by the relative investment into gametes via the gonadosomatic index GSI (Stockley et al., 1997; Stolz et al., 2005) and studies evaluating the reproductive success of spawners using DNA 
fingerprinting. These studies have been performed both in natural spawning systems (Colbourne et al., 1996; Foote et al., 1997; Mjolnerod et al., 1998; Hoysak et al., 2004; Reichard et al., 2004) and using in vitro fertilization trials (Withler, 1988; Withler and Beacham, 1994; Gage et al., 2004; Linhart et al., 2005; Kaspar et al., 2007; Yeates et al., 2007Kaspar et al., submitted;).

From the practical viewpoint of a hatchery manager, the extent of sperm competition is very important for the logistics of genetic programmes, because the common practice of pooling sperm from different males may have very detrimental effects if sperm competition levels are high (McKay and McMillan, 1991). Due to the potential for a high level of sperm competition, pooling sperm from different males may result in a much lower number of males being effectively represented in the offspring as numerically present in the competition, with predictable consequences of inbreeding and loss of genetic variability through genetic drift that such type of bottleneck is known to generate. Still, the extent of the problem may be very different according to the use of the hatchery products. If the only aim of the hatchery production is to stock ponds or tanks for growing fish to commercial size, a loss of genetic variability is not necessarily a problem, as it will not accumulate over time. Still, some advocate that a higher genetic variability helps to reduce the spread of diseases in a population (Springbett et al., 2003). However, if the stock produced aims at restocking natural populations or at being the basis of a selective breeding or domestication program (i.e. if the products are to be used as broodstock), then the loss of genetic variability will accumulate over time, together with inbreeding, and quickly produce negative effects on the performance of the population. This effect may have quite strong consequences, like hatchery strains which perform less in a farm environment than wild strains, as seen in tilapia in Asia (Eknath et al., 1993). 
This paper is not an original contribution but conceputally reviews sperm competition experiments that were conducted with common carp (Cyprinus carpio L.), and evaluates the genetic consequences of sperm competition in hatchery practice. Management procedures able to reduce these effects are discussed.

\section{THE DETERMINANTS OF SPERM COMPETITION IN COMMON CARP}

Sperm competition under hatchery conditions, when using pooled sperm, was confirmed in salmonids (Gharrett and Shirley, 1985; Withler, 1988; Withler and Beacham, 1994; Gage et al., 2004). These studies showed that sperm competition is a reality, and can lead to highly disequilibrated progeny numbers between males when using pools of sperm. It appears that the outcome of sperm competition is not necessarily linked to its fertilization success when used alone in fertilization control tests, neither to spermatocrit or sperm longevity (Withler, 1988; Gage et al., 2004). However, sperm velocity is correlated with competition success in Atlantic salmon (Gage et al 2004), and is considered to be a good predictor of sperm potency when equal numbers of spermatozoa per male are used in a pool (Wedekind et al., 2007).

In common carp it seems to be different. In a first experiment involving a series of male-to-male sperm competition trials, we showed that sperm competition was high, but that sperm velocity had no impact on the outcome of sperm competition (Linhart et al., 2005). On the contrary, both sperm motility (percentage of motile spermatozoa) and fertilization success in single trials could explain part of the differences between male potencies. Sperm motility accounted for $17.1 \%$ of the variance between males, and fertilization success in single trials for $32.5 \%$, still leaving $41.8 \%$ of the variance between males unexplained.

In a second experiment conducted with sperm pooled from five males, spermatocrit values, sperm motility, sperm velocity and hatching rate in separate 
tests all had an impact on the male potency. However, this still left a high proportion of the variation between the males unexplained (Kaspar et al., 2007).

A third experiment, also with sperm pooled from five males, showed that the sperm motility seems to be the main determinant of male potency (Kaspar et al., submitted). However, in this particular study, sperm motility was very low $(<5 \%)$ in two of the males used. This is expected to magnify the effect of motility on potency, when compared to other trials where all males had a high motility (>70\%). In the latter experiment, by fertilizing different egg batches with 5 000, 10 000, 20000 and 100000 spermatozoa per egg, using the same pool of 5 males, we also tested possible impact of the total number of spermatozoa per egg in the sperm pool on male potency. Undoubtedly it was demonstrated that total sperm concentration had no impact on male potency.

From the above it can be concluded that all recorded sperm parameters (spermatocrit, motility, velocity, single trial fertilization success) could have an impact on male potency in common carp, but that none of these can be considered as the main explanatory variable. This is in contrast to salmonids, where velocity seems to be the primary determinant of sperm competition success (Gage et al., 2004). Moreover, even with all parameters combined, a large proportion of the variance among males competitive success in sperm competition remains unexplained (Linhart et al., 2005; Kaspar et al., 2007).

\section{GENETIC CONSEQUENCES OF SPERM COMPETITION}

One of the main practical problems caused by sperm competition is unequal representation of males in hatchery progeny when pooled sperms are used for fertilization. This results in reduction of the effective size of the populations and a loss of genetic variability (e.g. McKay and McMillan 1991; Wedekind et al., 2007). 
Pooled sperm are frequently used in hatcheries to reduce the impact of males with low sperm quality on the overall fertilization rate, allowing the use of several males in a single fertilization in an attempt to maintain genetic variability.

The basic parameter that is modified by unequal male representation, linked to the amount of genetic variance lost at the next generation, is the effective number of males, $\mathrm{N}_{\mathrm{em}}$. This can be calculated as:

$$
\mathrm{N}_{\mathrm{em}}=\left(\mathrm{N}_{\mathrm{m}} \mathrm{k}_{\mathrm{m}}-1\right) /\left(\mathrm{k}_{\mathrm{m}}-1+\mathrm{V}_{\mathrm{m}} / \mathrm{k}_{\mathrm{m}}\right)
$$

Where $\mathrm{N}_{\mathrm{m}}$ is the number of males used, $\mathrm{k}_{\mathrm{m}}$ the mean number of progenies per male, and $\mathrm{V}_{\mathrm{m}}$ the variance of the number of progeny per male (Kimura and Crow, 1963). If all males have the same potency, any offspring has an equal chance to originate from each of the males used, and the number of progeny per male is expected to follow a Poisson distribution. In a Poisson distribution, the variance and mean are equal, then $\mathrm{k}_{\mathrm{m}}=\mathrm{V}_{\mathrm{m}}$. This simplifies equation 1 to:

$$
\mathrm{N}_{\mathrm{em}}=\mathrm{N}_{\mathrm{m}}-1 / \mathrm{k}_{\mathrm{m}}
$$

The latter will give the expected effective number of males if all males had the same reproductive success.

The above equations were used to estimate the expected and true values of $\mathrm{N}_{\mathrm{em}}$ in the mentioned 3 experiments on sperm competition in carp:

- In the first experiment (Linhart et al., 2005) 36 competition challenges between 2 males were performed with a total of 14720 offspring recorded. The theoretical $\mathrm{N}_{\mathrm{em}}$ in the absence of competition was 2.0 on average, and the true $\mathrm{N}_{\mathrm{em}}$ was 1.43 on average (1.02-1.98). This resulted in a mean reduction in $\mathrm{N}_{\mathrm{em}}$ of $28.4 \%$.

- In the second experiment (Kaspar et al., 2007), where equal volumes of sperm from 5 males were mixed and 250 offspring were evaluated, the 
theoretical $\mathrm{N}_{\mathrm{em}}$ was 4.98 , and the true $\mathrm{N}_{\mathrm{em}}$ was 2.87 , representing a $42.4 \%$ reduction.

- In V. Kaspar, K. Kohlmann, M. Vandeputte, M. Rodina, D. Gela, M. Kocour, S.M.H. Alavi, M. Hulak and O. Linhart; unpublished data, four trials were conducted with the same pool from 5 males, using different sperm:egg ratios. The expected $\mathrm{N}_{\mathrm{em}}$ was 4.93 on average, and the true $\mathrm{N}_{\mathrm{em}}$ ranged from 2.68 to 3.21 (mean 2.85), showing a mean reduction of $42.2 \%$.

The above show that using pooled sperm leads to a severe reduction of the effective number of males used. This can generate important reductions in genetic variability, if this technique is used in hatchery propagation of common carp broodstock. Similar calculations, using data published by Withler (1988) and Withler and Beacham (1994) in chinook salmon, give a mean reduction in $\mathrm{N}_{\mathrm{em}}$ equal to $31.4 \%$ (13-52\%), which is quite comparable to our results found for common carp.

\section{ALLEVIATING THE GENETIC CONSEQUENCES OF SPERM COMPETITION}

We now know that sperm competition arising from fertilization using pooled sperm can have severe consequences on the genetic variability in populations of common carp, the question arises of how to reduce these negative effects. With current hatchery practices in mind, the first recommendation would be to equalize the volume of sperm used from each male. In salmonids ignoring of this practice is expected to generate losses in $\mathrm{N}_{\mathrm{em}}$ in the range of $40-50 \%$ (Wedekind et al., 2007). Use of equal volumes of sperm from each male was tested in Kaspar et al. (2007), and generated a $42.4 \%$ reduction in $\mathrm{N}_{\mathrm{em}}$. In the same experiment, we also tried to set up a pool of sperm with equal number of spermatozoa per male, compensating 
spermatocrit differences by using unequal volumes of sperm from each male. Although this reduced the loss in $\mathrm{N}_{\mathrm{em}}(-34.9 \%$ instead of $-42.4 \%)$, the value remains high. Moreover, the other two experiments (Linhart et al., 2005; V. Kaspar, K. Kohlmann, M. Vandeputte, M. Rodina, D. Gela, M. Kocour, S.M.H. Alavi, M. Hulak and O. Linhart; unpublished data) both involved only competition tests with equal numbers of spermatozoa per male, and we previously found this to still generate high reductions in $\mathrm{N}_{\mathrm{em}}$. In chinook salmon, Withler and Beacham (1994) showed that holding a pool of sperm for 60 minutes prior to use allowed a good, if not total reequilibration of male contributions. Using the $\mathrm{N}_{\mathrm{em}}$ calculation approach with the data of Withler and Beacham (1994) the initial reduction in $\mathrm{N}_{\mathrm{em}}$ when the pool was used immediately was $32.8 \%$ on average, whereas it was only $7.6 \%$ when the pool was held for 60 minutes prior to fertilization. This approach was not tested in common carp, but could be interesting to assess in future, using more males than were previously tested in salmon (only 3 males were used, which is lower than the number practically used in hatcheries, which is 5 at least for a batch of eggs by in vitro fertilization in common carp).

Another possibility to reduce the consequences of sperm competition in common carp would be to divide eggs into batches equal to the number of males used and to fertilize them separately before combining them for incubation. This was tested in common carp in two experiments, where the males were identified with microsatellite markers. In the first experiment 24 males were crossed with 10 females in a full-factorial design (see Vandeputte et al., 2004 for details). The number of offspring assigned to parents was 524, the theoretical $\mathrm{N}_{\mathrm{em}}$ was 24.0 , and the true $\mathrm{N}_{\mathrm{em}}$ was 23.0 , resulting in a $4.2 \%$ reduction. In a second experiment, where 147 males were crossed with 8 females in a full factorial design (more details in Kocour et al., 
2007), 615 offspring were assigned to parents. The theoretical $\mathrm{N}_{\mathrm{em}}$ was 146.7 , and the true $\mathrm{N}_{\mathrm{em}}$ of 124.9 represents a reduction of $14.9 \%$. Thus, by using separate fertilizations of egg batches, it is possible to obtain male representations in progeny that are close to the optimum. For the time being, in the absence of a good predictor of a male's potency, the above approach could be recommended for the propagation of carp broodstocks in hatcheries.

The above is in line with theoretical studies which showed that factorial designs can reduce the variance in family sizes (Busack and Knudsen, 2007). Moreover, apart from the reduction of the variance in family sizes, factorial mating designs are also known to improve the conservation of genetic variance, either with or without selection (Dupont-Nivet et al., 2006), making their use even more beneficial. With a good predictor of a male's individual potency available, the use of factorial designs produced with pools of sperm could be an option. However, in the absence of such predictors, the use of separate fertilizations to produce factorial designs is highly recommended for the propagation of carp broodstocks in hatcheries. However, as outlined before, these recommendations are essential for hatchery batches that will generate the future broodstock for the next generation, but not necessarily for the mass production of fingerlings for stocking grow-out ponds, which should be much less affected by a reduction in genetic variability.

\section{Acknowledgements}

This work was supported by research plan of USB RIFCH no. MSM 6007665809, project of Grant Agency of the Czech Republic no. 524/06/0817 and project of National Agency for Agricultural Research no. QH82118. 


\section{References}

Birkhead, T.R.; Møller, A.P., 1998. Sperm competition, sexual selection and different routes to fitness. In: Birkhead, T.R.; Møller, A.P. (Eds.), Sperm Competition and Sexual Selection., Academic Press, London, 757-781. ISBN 0-12-100543-7.

Birkhead, T.R.; Pizzari T., 2002. Postcopulatory sexual selection. Nat. Rev. Genet. 3 , $262-273$.

Burness, G.; Casselman, S.J.; Schulte-Hostedde, A.I.; Moyes, C.D.; Montgomerie, R., 2004. Sperm swimming speed and energetic vary with sperm competition risk in bluegill (Lepomis macrochirus). Behav. Ecol. Socibiol. 56, 65-70.

Busack C.; Knudsen, C. M., 2007. Using factorial mating designs to increase the effective number of breeders in fish hatcheries. Aquaculture 273, 24-32.

Colbourne, J.K.; Neff B.D.; Wright J.M.; Gross M.R., 1996. DNA fingerprinting of bluegill sunfish (Lepomis macrochirus) using $(\mathrm{GT})_{\mathrm{n}}$ microsatellites and its potential for assessment of mating success. Can. J. Fish. Aquat. Sci. 53, 342349.

Dupont-Nivet, M.; Vandeputte, M.; Haffray, P.; Chevassus, B., 2006. Effect of different mating designs on inbreeding, genetic variance and response to selection when applying individual selection in fish breeding programs. Aquaculture 252, 161-170.

Eknath, A.E.; Tayamen, M.M.; Palada-de-Vera, M.S.; Danting, J.C.; Reyes, R.A.; Dionisio, E.E.; Capili, J.B.; Bolivar, H.L.; Abella, T.A.; Circa, A.V.; Bentsen, H.B.; Gjerde, B.; Gjedrem, T.; Pullin, R.S.V., 1993. Genetic improvement of farmed tilapias: the growth performance of eight strains of Oreochromis niloticus tested in different farm environments. Aquaculture 111, 171-188. 
Evans, J.P.; Magurran, A.E., 1999. Male mating behavior and sperm production characteristics under varying sperm competition risk in guppies. Anim. Behav. $58,1001-1006$.

Foote, C.J.; Brown, G.S.; Wood, C.C., 1997. Spawning success of males using alternative mating tactics in sockeye salmon, Oncorhynchus nerka. Can. J. Fish. Aquat. Sci. 54, 1785-1795.

Fuller, R.C., 1998. Sperm competition affects male behaviour and sperm output in the rainbow darter. Proc. R. Soc. Lond. B Biol. Sci.. 265, 2365-2371.

Gage, M.J.G.; MacFarlane, C.P.; Yeates, S., 2004. Spermatozoal traits and sperm competition in Atlantic salmon: Relative sperm velocity is the primary determinant of fertilization success. Curr. Biol. 14, 44-47.

Gharrett, A.J.; Shirley, S.M., 1985. A genetic examination of spawning methodology in a salmon hatchery. Aquaculture 47, 245-256.

Gross, M.R., 1985. Disruptive selection for alternative life histories in salmon. Nature 313, 47-48.

Kaspar, V.; Kohlmann, K.; Vandeputte, M.; Rodina, M.; Gela, D.; Kocour, M.; Alavi, S.M.H.; Hulak, M.; Linhart, O., 2007. Equalization of sperm concentrations in a pool of sperm does not prevent large variance in males contribution in common carp progeny. Aquaculture 272 S1, S204-S209.

Kaspar, V.; Hulak, M.; Kohlmann, K.; Vandeputte, M.; Rodina, M.; Gela, D.; Hulak, M.; Linhart, O. In vitro study on sperm competition in common carp (Cyprinus carpio L.). Submitted.

Kimura, M.; Crow, J.F., 1963. The measurement of effective population numbers. Evolution 17, 279-288. 
Kocour, M.; Mauger, S.; Rodina, M.; Gela, D.; Linhart, O.; Flajšhans, M.; Vandeputte, M., 2007. Heritability estimates for processing traits in common carp (Cyprinus carpio L.) using a molecular pedigree. Aquaculture 270, 43-50.

Leach, B.; Montgomerie R., 2000. Sperm characteristic associated with different male reproductive tactics in bluegills (Lepomis macrochirus). Behav. Ecol. Sociobiol. 49, 31-37.

Linhart, O.; Rodina, M.; Gela, D.; Kocour, M.; Vandeputte, M., 2005. Spermatozoal competition in common carp (Cyprinus carpio): what is the primary determinant of competition success? Reproduction 130, 1-8.

McKay, L.R.; McMillan, I., 1991. Effect of sperm pooling on inbreeding levels, Bull. Aquac. Assoc. Can. 3, 16-18.

Mjolnerod, I.B.; Fleming, I.A.; Refseth, U.H.; Hindar, K., 1998. Mate and sperm competition during multiple-male spawnings of Atlantic salmon. Can. J. Fish. Aquat. Sci 53, 2292-2298.

Parker, G.A., 1970. Sperm competition and its evolutionary consequences in the insects. Biol. Rev. 45, 525-567.

Parker, G.A.; Ball, M.A.; Stockley, P.; Gage, M.J.G., 1996. Sperm competition games: individual assessment of sperm competition intensity by group spawners. Proc. R. Soc. Lond. B Biol. Sci. 263, 1291-1297.

Parker, G.A., 1998. Sperm competition and the evolution of ejaculates: towards a theory base. In Sperm competition and sexual selection (ed. T. R. Birkhead \& A. P. Moller), London: Academic Press , 3-54.

Reichard, M.; Jurajda, P.; Smith, C., 2004. Male-male interference competition decreases spawning rate in the European bitterling (Rhodeus sericeus). Behav. Ecol. Sociobiol. 56, 34-41. 
Springbett, A.J.; MacKenzie, K.; Woolliams, J.A.; Bishop, S.C., 2003. The contribution of genetic diversity to the spread of infectious diseases in livestock populations. Genetics 165, 1465-1474.

Stockley, P.; Gage, M.; Parker, G.; Møller, A.P., 1997. Sperm competition in fishes: the evolution of testes size and ejaculate characteristics. Am. Nat. 149, 933954.

Stoltz, J.A.; Neff, B.D.; Olden, J.D., 2005. Allometric growth and sperm competition in fishes. J. Fish Biol. 67, 470-480.

Taborsky, M., 1994. Sneakers, satellites, and helpers: parasitic and cooperative behavior in fish reproduction. Adv. Study Behav. 23, 1-100.

Taborsky, M., 1998. Sperm competition in fish: 'bourgeois'males and parasitic spawning. Trends Ecol. Evol. 13, 222-227.

Taborsky, M., 1997. Bourgeous and parasitic tactics: do we need collective, functional terms for alternative reproductive behaviours? Behav. Ecol. Sociobiol. 41, 361-362.

Vandeputte, M.; Kocour, M.; Mauger, S.; Dupont-Nivet, M.; De Guerry, D.; Rodina, M.; Gela, D.; Vallod, D.; Chevassus, B.; Linhart, O., 2004. Heritability estimates for growth-related traits using microsatellite parentage assignment in juvenile common carp (Cyprinus carpio L.). Aquaculture 235, 223-236.

Vladic, T.V.; Jarvi, T., 2001. Sperm quality in the alternative reproductive tactics of Atlantic salmon: the importance of the loaded raffle mechanism. Proc. R. Soc. Lond. B Biol. Sci. 268, 2375-2381.

Wedekind, C.; Rudolfsen, G.; Jacob, A.; Urbach, D.; Muller, R., 2007. The genetic consequences of hatchery-induced sperm competition in a salmonid. Biol. Conserv. 137, 180-188. 
Withler, R.E., 1988. Genetic consequences of fertilizing chinook salmon (Oncorhynchus tshawytscha) eggs with pooled milt. Aquaculture 68, 15-25.

Withler, R.E.; Beacham, T.D., 1994. Genetic consequences of the simultaneous or sequential addition of semen from multiple males during hatchery spawning of chinook salmon (Oncorhynchus tshawytscha). Aquaculture 126, 11-23.

Yeates, S.; Searle, J.; Ward, R.G.; Gage, M.J.G., 2007. A two-second delay confers first-male fertilization precedence within in vitro sperm competition experiments in Atlantic salmon. J. Fish Biol. 70, 318-322. 